\title{
Stem Cell Factor Attenuates Liver Damage in a Murine Model of Acetaminophen-Induced Hepatic Injury
}

\author{
Kenneth Simpson, Cory M. Hogaboam, Steven L. Kunkel, David J. Harrison, \\ Cindy Bone-Larson, and Nicholas W. Lukacs
}

Department of Pathology (KS, DJH), University of Edinburgh, Edinburgh, United Kingdom; and Department of
Pathology (CMH, SLK, CB-J, NWL), University of Michigan, Ann Arbor, Michigan

SUMMARY: Acute liver injury is a common cause of intensive care unit visits. In these studies, we used a murine model of acetaminophen poisoning to examine the role of stem cell factor (SCF) on liver damage. In the initial studies, we identified that the liver produces relatively high constitutive levels of SCF. Upon administration of acetaminophen, the levels of SCF fell dramatically, correlating to damage within the liver. When the liver was allowed to regenerate, the levels of SCF again correlated with the liver regeneration. We next treated mice with anti-SCF before sublethal doses of acetaminophen and significantly increased lethality in anti-SCF-treated animals. When exogenous SCF was given to mice, the lethality was significantly reduced compared with the control acetaminophen-treated animals and the damage within the liver tissue was attenuated. The administration of rSCF reduced the level of steady-state mRNA for cytochrome P450 cyp2E1 enzyme both in vitro and in vivo. These data suggest that SCF functions as an important factor that protects livers from acute damage. (Lab Invest 2003, 83:199206).

\begin{abstract}
iver damage can be induced by infectious, phar-

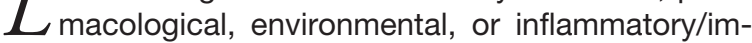
mune responses. Possibly one of the most common insults to the liver is accidental or purposeful acetaminophen poisoning, which seems to have a direct toxicity to the hepatocytes (Williams, 1996). The subsequent reaction is characterized by a massive damage of the liver, followed by intense inflammation and finally regeneration of the damaged tissue (Prescott and Critchley, 1983). This rapid progression of events takes only days to come to culmination, and the health of the host depends on protection from the toxic substance and efficient regeneration of the damaged hepatic tissue (Bisgaard and Thorgeirsson, 1996; Chanda and Mehendale, 1996). Several factors and cytokines may participate in the regeneration of the tissue, including hepatocyte growth factor, basic fibroblast growth factor, and several other growth factors that seem to influence directly the neoproliferation and differentiation of hepatocytes (Jiang and Hiscox, 1997; Kay and Fausto, 1997). Hepatotoxicity occurs from acetaminophen activation by microsomal cytochrome P450 mono-oxygenase conversion of acet-
\end{abstract}

\section{DOI: 10.1097/01.LAB.0000057002.16935.84}

Received November 4, 2002.

This work was supported by grants NIH-HL31237 and NIH-59178 (to $C M H, S L K, C B-L$, and NWL) and Scottish Hospital Endowments Research Trust 1512 (to KS and DJH).

Address reprint requests to: Dr. Nicholas W. Lukacs, University of Michigan Medical School, Department of Pathology, 1301 Catherine, Ann Arbor,MI 48109-0602.E-mail:nlukacs@umich.edu aminophen to a reactive metabolite, $\mathrm{N}$-acetyl-pbenzoquinone imine, binds to tissue macromolecules and initiates cellular death (Lee et al, 1996). There also seems to be a significant role for activation of oxidative pathways that lend to the damage and subsequently induce significant inflammation (Gibson et al, 1996). The toxicity of $\mathrm{N}$-acetyl-p-benzoquinone imine metabolite depends on several factors, including the ability to clear the toxic metabolite by glutathione trapping and the level of specific cytochrome P450 enzymes that are expressed by the hepatocyte for more rapid conversion of acetaminophen into $\mathrm{N}$-acetyl-p-benzoquinone imine (Allameh et al, 1997; Rathbun et al, 1996). In the present study, we examined the role of SCF in liver injury as a result of acetaminophen toxicity.

SCF has been predominantly depicted as a hematopoietic factor that induces leukocyte maturation and differentiation (Galli et al, 1994). However, recent evidence suggests that its production during disease might serve other important roles in structural tissue repair and protection (Costa et al, 1996; Wershil et al, 1992). SCF is initially found as a transmembrane protein that is enzymatically cleaved from the surface of cells during injury and inflammation. In this manner, it seems that several cell populations can express SCF and quickly released upon cellular assault or inflammation. Not only is SCF a growth factor for melanocytes found in the skin, it also seems to be associated with other cell populations, in particular hepatocytes (Rao et al, 1996). In addition, SCF and its receptor, c-kit, have been shown to be expressed on numerous 
types of tumor cells, including neuroblastomas, small cell lung adenocarcinoma, and hepatomas (Bar-Eli, 1997; Beck et al, 1995; Fujio et al, 1994; Papadimitriou et al, 1995; Ricotti et al, 1998). Finally, SCF has been shown to attenuate radiation-induced injury by attenuating the oxidative activation pathways in several cell populations, indicating that it may have an overall protective effect for cells (Leigh et al, 1995; Turner et al, 1992; Zsebo et al, 1992). Previous studies have indicated that the presence of SCF within the liver is localized in hepatocytes and ductal epithelial cells (Alison et al, 1996; Liebmann et al, 1994; Omori et al, 1997). Thus, SCF may serve not only as an important growth factor but also as a protective factor in tissue that may be susceptible to environmental/toxic injury, such as melanocytes and hepatocytes.

In the present study, we examined the role of SCF in the liver using a murine model of acetaminopheninduced liver toxicity. The data indicate that a significant amount of SCF can be found constitutively in the liver of normal mice and subsequently is drastically decreased during the injury, corresponding to hepatocyte damage. As the liver begins to recover and starts the regenerative process, SCF levels recovered and correlated to the hepatocyte proliferation. Neutralization of SCF during the acetaminophen response significantly attenuates the regeneration, leaving more liver damage. Likewise, when exogenous SCF was given to the acetaminophen-treated animals, lethality was abrogated. Overall, these studies indicate a significant role for SCF in liver function and protection from injury.

\section{Results}

\section{Acetaminophen-Induced Liver Damage Correlates with Decreased SCF Levels}

For determining the level of acetaminophen that was necessary to induce liver damage, a dose response was performed. The preliminary studies indicated that a sublethal dose of $200 \mathrm{mg} / \mathrm{kg}$ could induce significant liver pathology with relatively little lethality, whereas $300 \mathrm{mg} / \mathrm{kg}$ induced catastrophic liver damage and was $80 \%$ lethal by 48 hours (Fig. 1). We were next interested in whether SCF levels were altered in the liver. Figure 2 indicates that in animals treated with either a low or a high dose of acetaminophen, a significant decrease in SCF levels that correlated with hepatic damage could be observed. In the low dosetreated animals, which recover from the injury, the SCF levels begin to rebound by Day 2 and continue to rise at Day 4 and Day 6, when livers seemed to be normal histologically. The levels of SCF at Day 6 were similar to control livers. In the high-dose acetaminophen treatment, the SCF levels in the liver demonstrated a significant decrease with no recovery, correlating with the lack of liver regeneration and death. In addition, the serum levels of SCF showed an increase in SCF at 6 to 12 hours after acetaminophen (Fig. 3), suggesting a release from the damaged liver into circulation.

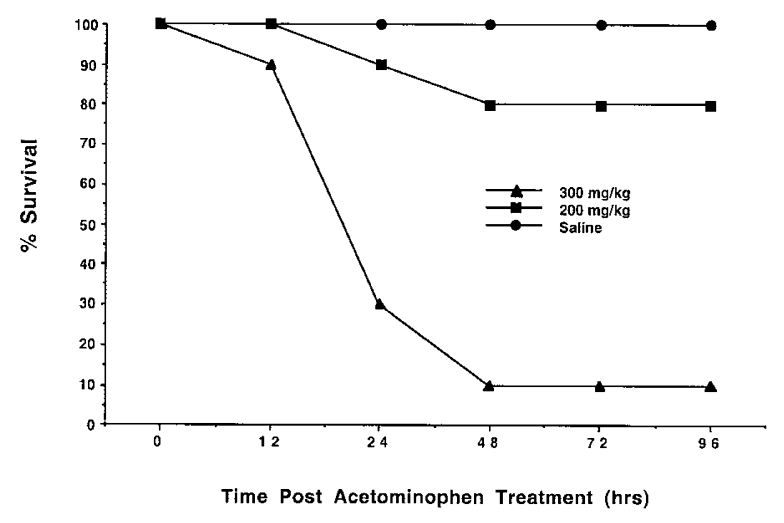

Figure 1.

Lethality in mice treated with a sublethal $(200 \mathrm{mg} / \mathrm{kg})$ or a lethal $(300 \mathrm{mg} / \mathrm{kg})$ dose of acetaminophen. Normal CBA/J mice were fasted for 8 hours and subsequently given an intraperitoneal injection of acetaminophen dissolved in PBS or PBS alone for control. Mouse survival was followed for 4 days when the experiment was terminated. Data represent percentage survival of 20 mice/group from two separate experiments.

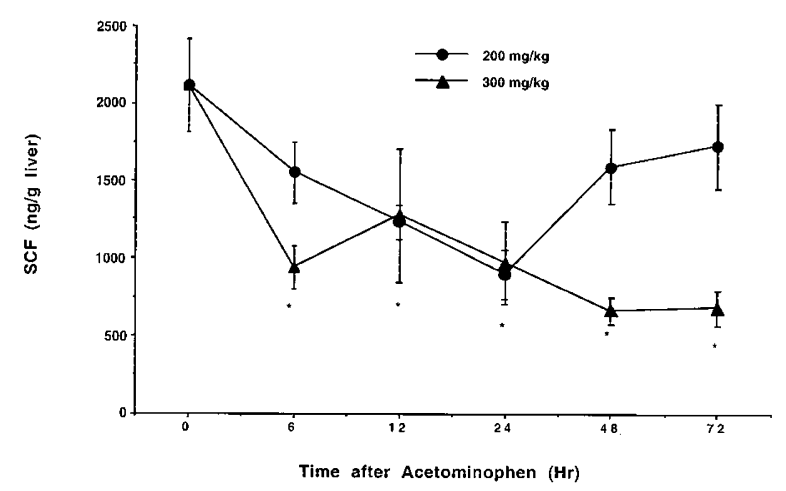

Figure 2.

Liver stem cell factor (SCF) levels in mice treated with lethal $(300 \mathrm{mg} / \mathrm{kg})$ or sublethal $(200 \mathrm{mg} / \mathrm{kg})$ doses of acetaminophen. A portion of the liver from killed mice was taken and weighed immediately after extraction at various time points after acetaminophen administration. The liver tissue was ground in PBS with $0.1 \%$ Triton X-100 containing anti-proteases, and the cell-free supernatant was assayed in an SCF-specific enzyme-linked immunosorbent assay (ELISA). The data represent mean \pm SE from at least six mice per time point; ${ }^{\star} p=0.05$.

\section{Neutralization of SCF during Acetaminophen Poisoning}

To determine the role of SCF in acetaminopheninduced liver tissue, we passively immunized animals with anti-SCF antibody intraperitoneally 1 hour before low-dose acetaminophen treatment. In mice that were given anti-SCF, only $40 \%$ survived compared with the control antibody-treated group, in which $80 \%$ of the animals survived (Fig. 4). The anti-SCF-treated group demonstrated a significant increase in lethality as analyzed by $\chi^{2}$ analysis. Livers from the treated animals that survived were then examined by histology, and the necrotic areas were measured morphometrically. The level of damage at Day 4 (a time when recovery was normally beginning in acetaminophentreated animals) demonstrated a significant increase in necrotic area in anti-SCF-treated animals (Fig. 5). These data suggested increased damage and/or a lower level of regeneration in SCF-depleted animals. 


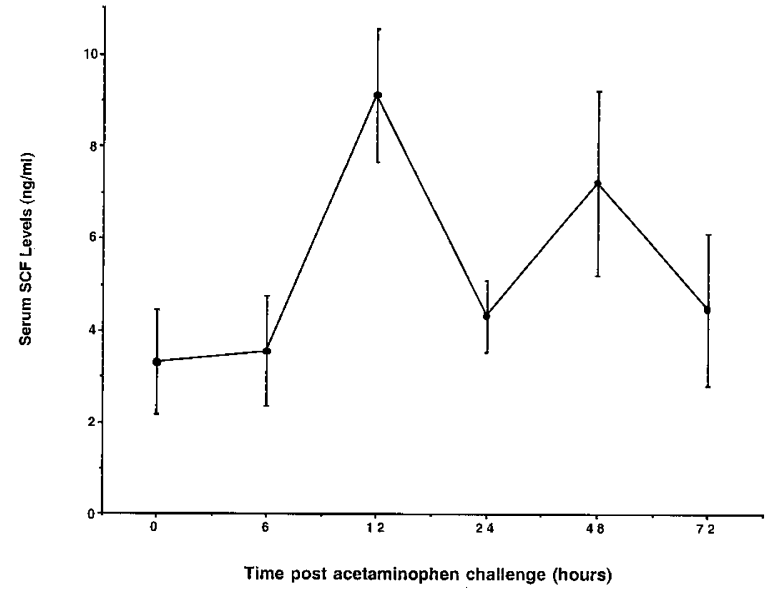

Figure 3.

Serum SCF levels after acetaminophen administration. Whole blood was collected from acetaminophen-treated mice at various time points postchallenge. Serum was collected, and SCF levels were assessed using our specific ELISA. The data represent the mean $\pm \mathrm{SE}$ from four to five mice per time point. Normal serum SCF levels in human and mouse samples range from 3 to $5 \mathrm{ng} / \mathrm{ml}$.

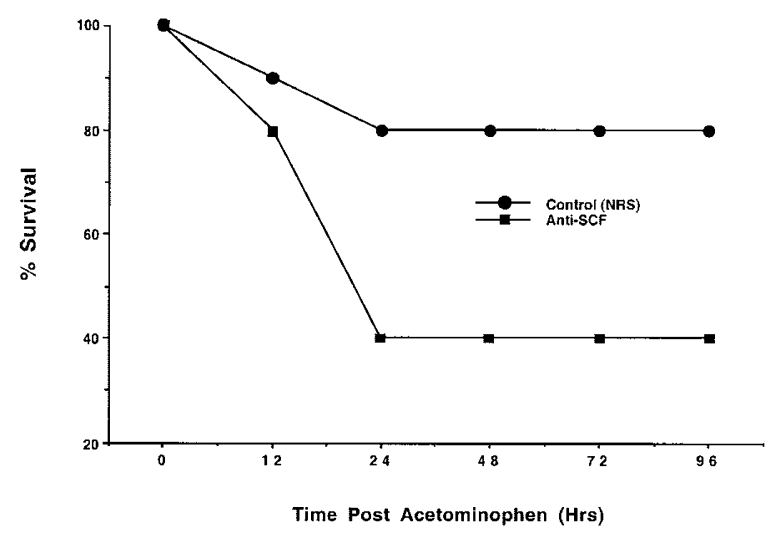

Figure 4.

Neutralization of SCF exacerbates acetaminophen-induced lethality. Animals were treated with control or anti-SCF-specific serum 1 hour before administration of a sublethal dose of acetaminophen. The survival of animals was recorded for 4 days and terminated. Livers were harvested and examined histologically. Data represent percentage survival from two separate experiments with a total of 20 mice in each treatment group.

\section{Exogenous SCF Protects Mice from a Lethal Acetaminophen Dose}

For determining whether SCF has a role in protecting the animals from acetaminophen toxicity, $1 \mu \mathrm{g}$ of recombinant murine SCF was injected intraperitoneally at the time of acetaminophen challenge. As shown in Figure 6, when animals were given exogenous SCF, they were protected from a lethal dose of acetaminophen, with $90 \%$ of the animals surviving compared with only $30 \%$ of the control animals surviving. The SCF-treated group demonstrated a significant increase in survival as determined by $\chi^{2}$ analysis. These data were followed by examination of liver damage after acetaminophen treatment. When liver enzymes ALT and AST were examined, there was a significant decrease in the rSCF-treated group compared with the control group at 24 hours postchallenge (Fig. 6B), correlating with the survival data.

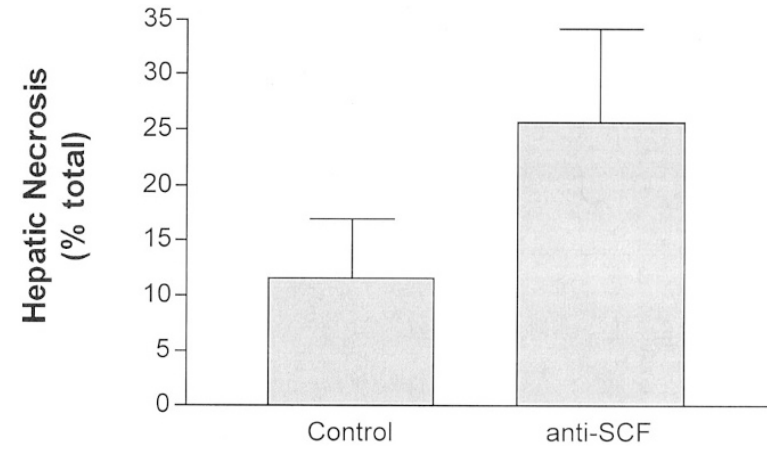

Figure 5.

Mice treated with anti-SCF have increased necrotic areas of the liver. Animals were treated with control or anti-SCF-specific serum 1 hour before administration of a sublethal dose of acetaminophen. The survival of animals was recorded for 4 days and terminated. Sections of liver tissue (two from each animal) were stained with hematoxylin and eosin, and the area of hepatic damage was determined morphometrically and expressed as a percentage of total liver area examined. Data represent mean \pm SE from at least eight mice per group. Anti-SCF-treated animals had a significantly increased necrotic area compared with control serum-treated animals $(p<0.05)$.
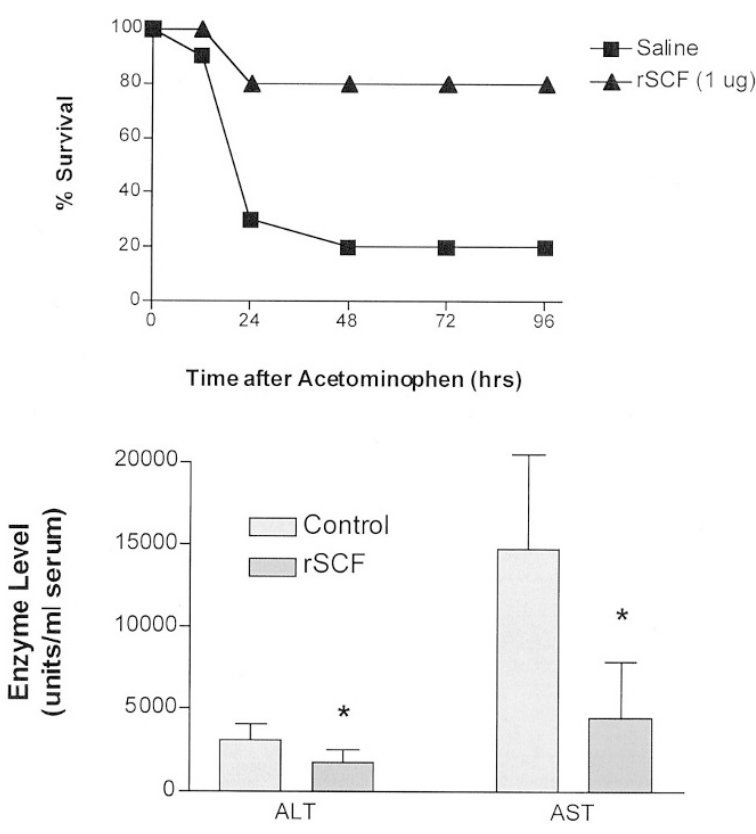

Figure 6.

Exogenous treatment with recombinant SCF increases survival (A) and reduced serum liver enzymes in animals treated with a lethal dose of acetaminophen. Animals were treated with $1 \mu \mathrm{g}$ of recombinant SCF or saline within 30 minutes of acetaminophen administration $(300 \mathrm{mg} / \mathrm{kg})$. The survival of animals was recorded for 6 days and the experiment was terminated. Data represent percentage survival from two separate experiments with a total of 20 mice in each treatment group. Liver enzyme levels were examined after 24 hours after acetaminophen treatment $(300 \mathrm{mg} / \mathrm{kg})$ with or without SCF treatment $(1$ $\mu \mathrm{g} /$ mouse intraperitoneally). The data in Figure $6 \mathrm{~B}$ represent the mean $\pm \mathrm{SE}$ from six to seven mice per group.

Thus, Figure 6 depicts the ability of exogenous SCF to attenuate the damage of the liver. Histologically, the livers from the mice that were given rSCF seemed to have minimal damage (Fig. 7) throughout the course of injury and recovery, whereas the livers from controltreated animals had significant damage and necrotic areas with hemorrhage. 
APAP
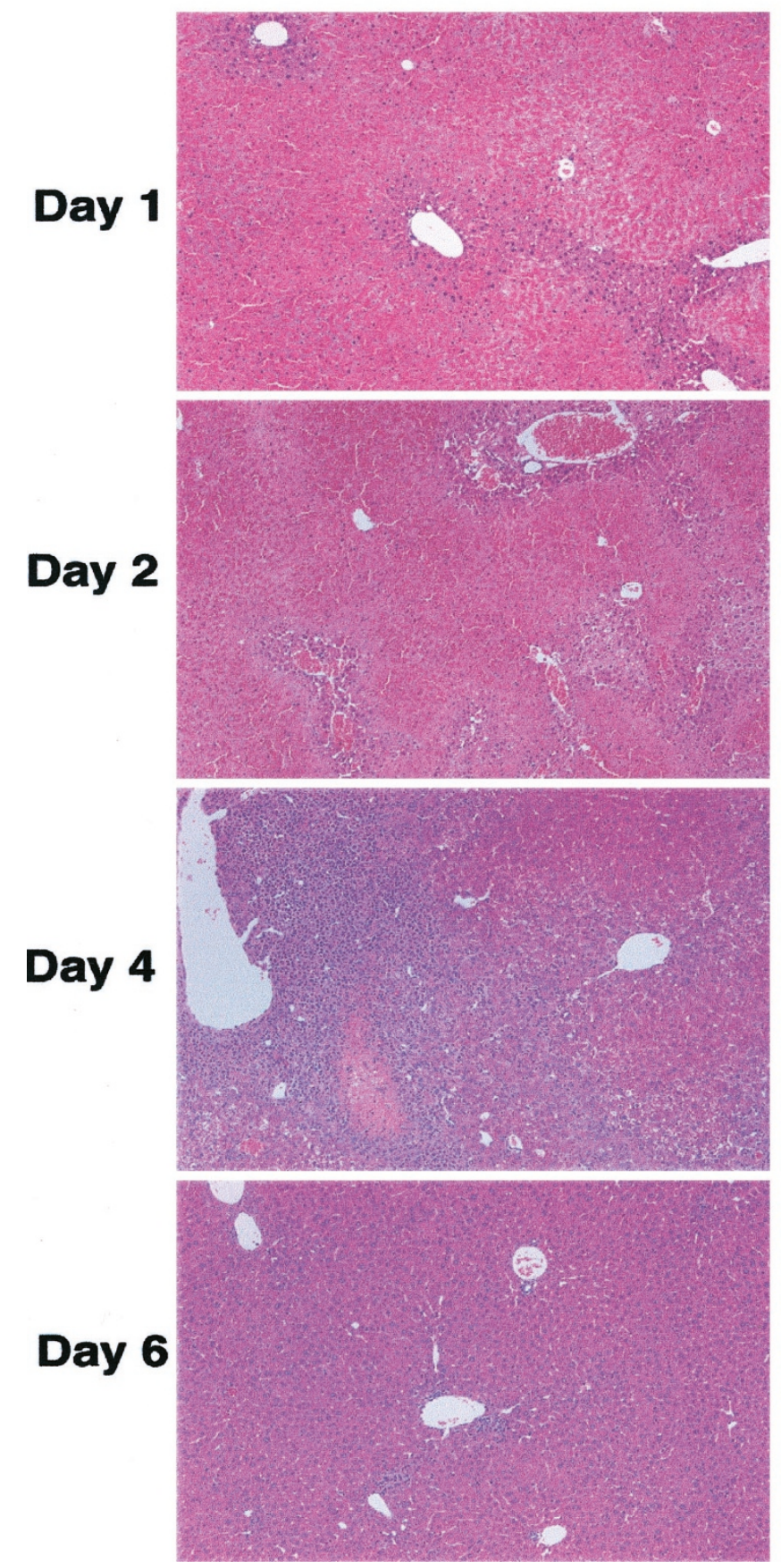

+ SCF
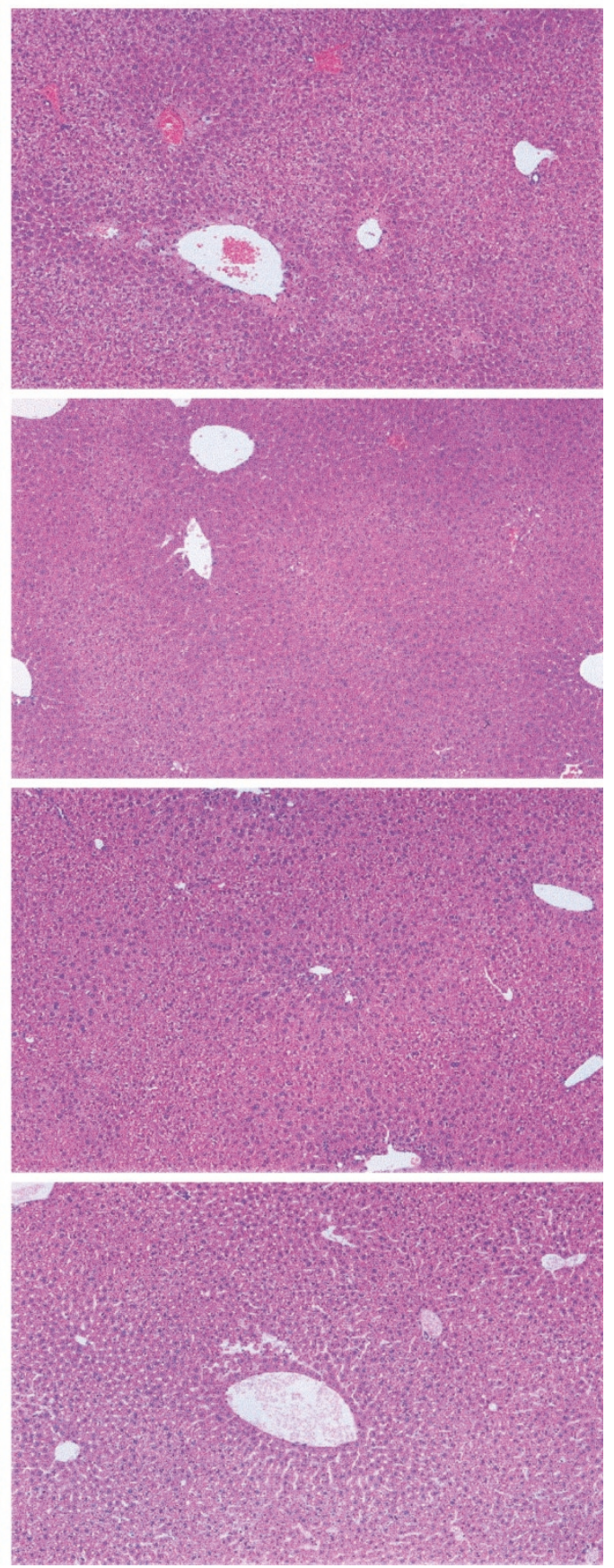

\section{Figure 7.}

Livers from animals given exogenous SCF have no evidence of damage histologically at 4 days after lethal acetaminophen ( $300 \mathrm{mg} / \mathrm{kg})$ administration. Animals were treated with $1 \mu \mathrm{g}$ of recombinant SCF or saline within 30 minutes of acetaminophen administration (300 mg/kg). The survival of animals was recorded for 4 days and the experiment was terminated. The livers were examined histologically and demonstrated that animals treated with recombinant SCF had minimal necrotic area (A), whereas large areas of damage could easily be found in saline-treated animals (B).

\section{SCF Attenuates Cytochrome P450 cyp2E1 Expression}

For understanding better the function of SCF in protecting hepatocytes from damage by acetaminophen, livers from mice that were treated with acetaminophen with or without SCF and a hepatocyte cell line, N muli, were used. One of the possible mechanisms that were affected in these responses was the enzyme cytochrome P450 cyp2E1, which converts acetaminophen into its toxic metabolite; $\mathrm{N}$-acetyl-p-benzoquinone imine is regulated by SCF. Experiments with livers from mice indicated that there seemed to be a difference in the expression of cytochrome P450 cyp2E1 mRNA in SCF-treated (1 $\mu \mathrm{g} / \mathrm{mouse})$ compared with untreated mice early during the response at 1 hour as analyzed by reverse transcription polymerase chain reaction (RT-PCR; Fig. 8). It is interesting that our 
analysis indicates significant levels of constitutive mRNA for p450 cyp2E1 in untreated control mice. By the later, 4-hour, time point, the difference was not evident.

It is often difficult to estimate the expression patterns properly from whole-tissue extracts. Therefore, we also examined the expression of cytochrome P450 cyp2E1 mRNA in an in vitro cultured cell line. When the hepatocyte line $\mathrm{N}$ muli was exposed to acetaminophen in the presence of increasing concentrations of SCF, an attenuation of the acetaminophen-induced cellular damage was observed (data not shown). The analysis of mRNA for P450 expression in $\mathrm{N}$ muli hepatocytes after exposure to acetaminophen (2.0 $\mathrm{mm}$ ) with or without SCF demonstrated a significant regulatory function for SCF (Fig. 9), similar to that observed within the liver of treated mice.

\section{Discussion}

The protection and regeneration of liver tissue after damage is an area of intense investigation. It seems that multiple factors may be involved, including several cytokines and cellular interactions (Bisgaard and Thorgeirsson, 1996; Chanda and Mehendale, 1996). In this study, we were interested in examining the involvement of SCF in liver damage and recovery. Previous studies have indicated that the presence of SCF in liver tissue was localized within the bile duct epithelial cells (Omori et al, 1997), an area of the liver that seems to be a site for stem cell localization (Alison et al, 1996). When SCF was measured from liver samples, a high constitutive level was observed in normal livers that were significantly decreased as the hepatic damage was induced with the acetaminophen treatment. SCF is initially expressed as a transmembrane protein on the surface of cells and subsequently cleaved during inflammatory events (Galli et al, 1994). The decreased levels of liver SCF during acetaminophen challenge may indicate a release of transmembrane SCF to soluble. This release was indicated by the increase of SCF into the serum of treated animals. Thus, transmembrane SCF may serve as a "reservoir" for quick release upon injury to protect the liver tissue.

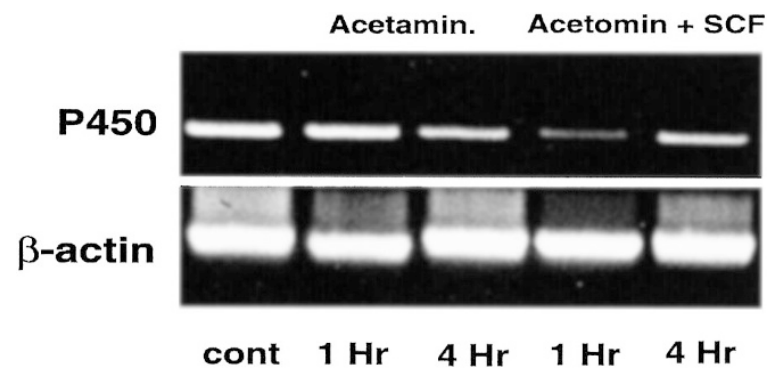

Figure 8.

SCF inhibits acetaminophen-induced cytochrome P450 cyp2E1 in livers of challenged mice. Animals were treated with $1 \mu \mathrm{g}$ of recombinant SCF or saline within 30 minutes of acetaminophen administration $(300 \mathrm{mg} / \mathrm{kg})$. Livers were harvested at 1 and 4 hours after acetaminophen challenge to examine the early P450 cyp2E1 expression by RT-PCR analysis. Data are representative of expression in three to four mice per group.

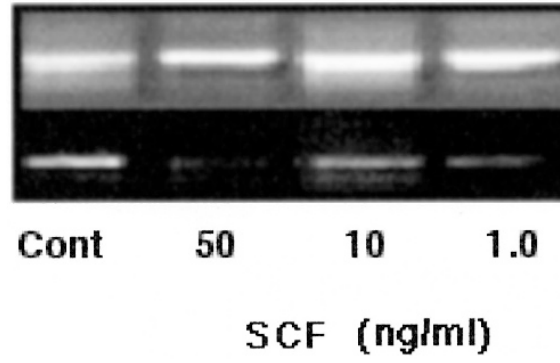

Actin

$\mathrm{P} 450$

Figure 9.

SCF inhibits acetaminophen-induced cytochrome P450 cyp2E1 mRNA expression. The mouse hepatocyte line $\mathrm{N}$ muli was serum starved for 36 hours and then exposed to acetaminophen $(2.0 \mathrm{~mm})$ with or without increasing doses of SCF. The analysis of cytochrome P450 cyp2E1-specific mRNA by RT-PCR demonstrates that SCF inhibits the expression 4 hours after acetaminophen treatment. Data are representative of three repeat experiments.

The hepatic SCF levels then raised again as the tissue began to regenerate and returned to control levels by 4 to 6 days after acetaminophen treatment, a time when the tissue appeared near normal when the histology was examined. Although the latter data show only correlative data, the anti-SCF treatment demonstrated a significant increase in lethality to a sublethal dose of acetaminophen. In addition, there was a higher level of tissue damage at Day 4 after SCF neutralization. Treatment of mice with exogenous SCF (40 $\mu \mathrm{g} / \mathrm{kg}$ ) drastically attenuated acetaminopheninduced damage within the liver. Thus, SCF seems to be a very potent endogenous modulator of liver damage.

These data can be interpreted several ways. First, SCF may have direct effects on hepatocyte growth and differentiation either by directly inducing hepatocyte growth or by blocking necrosis and/or apoptosis of hepatocytes during damage. SCF has a wellrecognized role in controlling cell proliferation and differentiation in hemopoietic cells, germ line cells, and melanocytes. Expression of both SCF and c-kit (the SCF receptor) were induced after partial hepatectomy and arylamine 2-acetylaminofluorene (AAF), but no induction was noted with either treatment alone (Fujio et al, 1994). Furthermore, the expression of c-kit was restricted to oval cells in the latter study (Fujio et al, 1994). Liver regeneration after either toxic liver injury or partial hepatectomy occurs via proliferation of hepatocytes, rather than expansion of the oval cell compartment. SCF has also been implicated in the development of differentiated hepatocytes in the pancreas of rodents subjected to copper depletion and repletion and in the bile ductular proliferation induced in immature areas after bile duct ligation (Rao et al, 1996). Hepatoblastomas are able to synthesize SCF (Lukacs et al, 1996); this may play a role in the extramedullary hemopoiesis observed in fetal liver. In addition, SCF can synergize with hepatocyte growth factor and erythropoietin in the proliferation of bone marrow stem cells (Galimi et al, 1994; Von Schweinitz et al, 1995). The synergistic effects of SCF and erythropoietin are mediated via the flt-flt-3 tyrosine kinase signaling system, which has also been implicated in 
bile ductular proliferation after bile duct ligation (Omori et al, 1997). SCF may also modulate the Jak-Stat3 pathway, a pathway also implicated in liver regeneration (Jacobs-Helber et al, 1997). Ongoing studies in our laboratories indicate that SCF can directly induce hepatocyte proliferation in vitro and that hepatocytes express cleavable SCF on their surface (preliminary data). SCF has been demonstrated to be involved in proliferation and differentiation of potential hepatocyte progenitor populations within the liver, thus suggesting an interesting link with the present studies (Gotoh et al, 1996).

An alternative hypothesis may be that SCF could "protect" the liver tissue from toxic injury. This would follow that SCF has been shown to attenuate radiation-induced injury in multiple cell populations (Leigh et al, 1995; Zsebo et al, 1992), an event that relies on oxidative metabolites. The data from this study demonstrate that SCF levels actually fall during damage and do not return until regeneration has occurred. In addition, that livers have high constitutive levels of SCF may suggest that its persistence within the liver may be necessary to protect cells from damage. The anti-SCF treatment may merely reduce that level of protection and increase the damage induced by acetaminophen treatment. These studies were further followed up by administration of exogenous SCF. The effects of the lethal dose could be almost totally abrogated by giving SCF at the time of acetaminophen poisoning, indicating a possible therapeutic role for SCF in liver damage. Using in vitro cultured hepatocytes, SCF was shown to protect the hepatocytes from acetaminophen-induced damage, at least in part, by down-regulating cytochrome P450 cyp2E1 expression. This would presumably alter the conversion of acetaminophen into its toxic form (Nacetyl-p-benzoquinone imine) and reduce the damage (Lee et al, 1996).

There is a paucity of data concerning the role of SCF during disease. SCF is most notably known for its hematopoietic ability for growth and differentiation of bone marrow-derived cells, including erythrocytes, lymphocytes, and neutrophils, as well as being required for mast cell growth, differentiation, and survival (Galli et al, 1994). It is interesting that the fetal liver is a prominent site for hematopoiesis, and it is no surprise that SCF would be made within these tissues (Emerson, 1990; Timens and Kamps, 1997). However, the production of constitutive levels of SCF into adulthood, a time when the hematopoietic activity of the liver is minimal, may indicate that SCF has alternative functions. Recent data from our laboratory have indicated that SCF not only protects mice from septic shock but also upregulates STAT3 activation in livers (Bone-Larson et al, 2000). Of special interest is the success of a c-kit-associated tyrosine kinase inhibitor STI571, a treatment for chronic myelegenous leukemia (CML) (Inokuchi et al, 2000; Mauro and Druker, 2001). These issues outlined in this report may have a significantly impact on the regiment of the latter treatment.
These data suggest that SCF is produced within the liver and may have alternative functions other than a hematopoietic factor. The correlation of SCF levels with liver regeneration and the neutralization data that indicate higher levels of damage in animals treated with anti-SCF indicates that SCF plays an important role in the health of the liver during disease pathogenesis. Future studies will be aimed at examining the mechanistic role of SCF on hepatocyte damage and growth.

\section{Materials and Methods}

\section{Experimental Model}

Six-week-old female CBA/J mice (Jackson Laboratory, Bar Harbor, Maine) were fasted, but with free access to water, for 8 hours before intraperitoneal injection of acetaminophen (Sigma, St. Louis, Missouri) at 200 or $300 \mathrm{mg} / \mathrm{kg}$, dissolved in normal saline. After injection, the animals were allowed free access to food. Mice were killed, and liver was taken from the mice at various time points after acetaminophen injection into the mice.

\section{Production of Anti-SCF Antibodies}

Rabbit anti-murine SCF antibodies were prepared by multiple-site immunization of New Zealand white rabbits with recombinant murine SCF (Genzyme, Cambridge, Massachusetts) in complete Freund's adjuvant (CFA). Polyclonal antibodies were titered by direct enzyme-linked immunosorbent assay (ELISA) and specifically verified by the failure to cross-react to mIL-3, mIL- $1 \alpha$, mTNF, mMIP- $1 \alpha$, IL-6, mJE, mMIP- $1 \beta$, hMCP-1, hIL-8, hRANTES, hMIP- $1 \alpha$, hTNF, and hMIP$1 \beta$. The immunoglobulin $\mathrm{G}$ portion of the serum was purified over a protein $A$ column and used in a sandwich ELISA and for immunohistochemical staining. The quality of the antibodies was assessed by using in vitro assays consisting of blocking SCFinduced mast cell activation and migration as previously described (Lukacs et al, 1996). These antibodies could completely inhibit $100 \mathrm{ng} / \mathrm{ml}$ SCF in the mast cell assay at a 1:500 dilution.

\section{SCF ELISA}

SCF was quantitated by ELISA using a modification of a double ligand method as previously described (Lukacs et al, 1996). Briefly, flat-bottomed 96-well microtiter plates (Nunc Immuno-Plate I 96-F, Denmark, Netherlands) were coated with $50 \mu \mathrm{l} /$ well rat anti-SCF monoclonal antibody $(1 \mathrm{ng} / \mu \mathrm{l}$ in $0.6 \mathrm{M} \mathrm{NaCl}$, $0.26 \mathrm{M} \mathrm{H}_{3} \mathrm{BO}_{4}$, and $0.08 \mathrm{~N} \mathrm{NaOH}, \mathrm{pH}$ 9.6) for 16 hours at $4^{\circ} \mathrm{C}$ and then washed with phosphate-buffered saline (PBS), $\mathrm{pH} 7.5$, and $0.05 \%$ Tween-20 (wash buffer). Nonspecific binding sites were blocked with $2 \%$ bovine serum albumin in PBS and incubated for 90 minutes at $37^{\circ} \mathrm{C}$. Plates were rinsed four times with wash buffer, and diluted (1:2 and 1:10) cell-free supernatants in duplicate were added, followed by incubation for 1 hour at $37^{\circ} \mathrm{C}$. Plates were washed four times, 
followed by the addition of $50 \mu \mathrm{l} /$ well biotinylated rabbit anti-SCF antibody $(3.5 \mathrm{ng} / \mu \mathrm{l}$ in PBS [pH 7.5], $0.05 \%$ Tween-20, and $2 \%$ fetal calf serum), and plates were incubated for 30 minutes at $37^{\circ} \mathrm{C}$. Plates were washed four times, streptavidin-peroxidase conjugate (Bio-Rad Laboratories, Richmond, California) was added, and the plates incubated for 30 minutes at $37^{\circ} \mathrm{C}$. Plates were again washed four times, and chromogen substrate was (Bio-Rad Laboratories) added. The plates were then incubated at room temperature to the desired extinction, and the reaction was terminated with $50 \mu \mathrm{l} /$ well $3 \mathrm{M} \mathrm{H}_{2} \mathrm{SO}_{4}$ solution. Plates were read at $490 \mathrm{~nm}$ in an ELISA reader. Standards were 1/2 log dilutions of recombinant SCF from $10 \mathrm{pg} / \mathrm{ml}$ to $100 \mathrm{ng} / \mathrm{ml}$. This ELISA method consistently detected SCF concentrations above 250 $\mathrm{pg} / \mathrm{ml}$. The SCF antibody ELISA did not cross-react with $\mathrm{mIL}-3, \mathrm{mIL}-1 \alpha$, mTNF, mMIP-1 $\alpha$, IL-6, mJE, mMIP-1 $\beta$, hMCP-1, hIL-8, hRANTES, hMIP- $1 \alpha$, hTNF, and hMIP-1 $\beta$.

\section{In Vivo Neutralization of SCF}

Neutralization of SCF was carried out using a polyclonal rabbit anti-murine SCF antibody developed in our laboratory as above. The protein A column purified anti-SCF or control antibody was intraperitoneally 1 hour before acetaminophen treatment. Likewise, paraffin-embedded liver sections were stained and the damage was quantified at the various time points postchallenge.

\section{Assessment of Hepatic Repair and Injury}

Hepatic damage was measured using an AXIO-HOME microscope by two independent investigators (KJS and DJH). Sections of liver tissue (two from each animal) were stained with hematoxylin and eosin, and the area of hepatic damage was outlined and expressed as a percentage of total liver area examined.

\section{Culture of N Muli Hepatocyte Cell Line}

$\mathrm{N}$ muli (ATCC \#CRL 1638) were cultured in Dulbecco's modified Eagle's medium with 15\% fetal bovine serum as recommended. The cells were trypsinized from confluent flasks and cultured in 96-well plates for proliferation assays and 6-well plates for isolation for cytochrome P450 mRNA expression. The cells were given an injurious dose of acetaminophen (1.7 mM) with or without increasing concentrations of SCF. For mRNA analysis, cells were harvested after 4 hours from six-well plates.

\section{RT-PCR of N Muli Cell Line and Liver mRNA}

Five micrograms of total RNA from specific samples was reversed transcribed into cDNA with the use of a $B R L$ reverse transcription kit and oligo (dT) 12 to 18 primers. Primers (taken from the above published sequences) were generated using a computerassisted system AMPLIFY, which allows one to predict primer interactions that will give a single amplified product. The primer sequence used for P450 cyp2E1 was 5'-CTGATTGGCTGTGCACCCTG-3' sense and 5'-FACTTAAGGTG TTCCTTGGC-3 antisense. The amplification buffer contained $50 \mathrm{~mm} \mathrm{KCl,} 10 \mathrm{~mm}$ Tris- $\mathrm{HCl}$ ( $\mathrm{pH} 8.3$ ), and $2.5 \mathrm{~mm} \mathrm{MgCl}$. Specific oligonucleotide primers were added (200 ng/sample) to the buffer, along with $1 \mu \mathrm{l}$ of the reverse-transcribed cDNA sample. The cDNA was amplified using the following cycling parameters: The mixture was first incubated for 5 minutes at $94^{\circ} \mathrm{C}$ and then cycled 30 times at $95^{\circ} \mathrm{C}$ for 30 seconds, $55^{\circ} \mathrm{C}$ for 45 seconds, and elongated at $72^{\circ} \mathrm{C}$ for 75 seconds. This format allowed optimal amplification with a minimum of nonspecific amplification of any contaminating cDNA. After amplification, the sample $(20 \mu \mathrm{l})$ was separated on a $2 \%$ agarose gel containing $0.3 \mu \mathrm{g} / \mathrm{ml}$ ethidium bromide, and bands were visualized and photographed using a translucent ultraviolet source.

\section{Statistical Analysis}

Statistical significance was determined by $\chi^{2}$ analysis of lethality curves and analysis of variance for other analysis.

\section{References}

Alison MR, Golding MH, and Sarraf CE (1996). Pluripotential liver stem cells: Facultative stem cells located in the biliary tree. Cell Prolif 29:373-402.

Allameh A, Vansoun EY, and Zarghi A (1997). Role of glutathione conjugation in protection of weanling rat liver against acetaminophen-induced hepatotoxicity. Mech Ageing Dev 95(1-2):71-79.

Bar-Eli M (1997). Molecular mechanisms of melanoma metastasis. J Cell Physiol 173:275-278.

Beck D, Gross N, Brognara CB, and Perruisseau G (1995). Expression of stem cell factor and its receptor by human neuroblastoma cells and tumors. Blood 86:3132-3138.

Bisgaard HC and Thorgeirsson SS (1996). Hepatic regeneration. The role of regeneration in pathogenesis of chronic liver diseases. Clin Lab Med 16:325-339.

Bone-Larson CL, Hogaboam CM, Steinhauser ML, Oliveira SH, Lukacs NW, Strieter RM, and Kunkel SL (2000). Novel protective effects of stem cell factor in a murine model of acute septic peritonitis. Dependence on MCP-1. Am J Pathol 157:1177-1186.

Chanda S and Mehendale HM (1996). Hepatic cell division and tissue repair: A key to survival after liver injury. Mol Med Today 2:82-89.

Costa JJ, Demetri GD, Harrist TJ, Dvorak AM, Hayes DF, Merica EA, Gringeri DM, Schwartz LB, and Galli SJ (1996). Recombinant human stem cell factor (kit ligand) promotes human mast cell and melanocyte hyperplasia and functional activation in vivo. J Exp Med 183:2681-2686.

Emerson SG (1990). The regulation of hematopoiesis in the fetal liver. Prog Clin Biol Res 352:21-28.

Fujio K, Evarts RP, Hu Z, Marsden ER, and Thorgeirsson SS (1994). Expression of stem cell factor and its receptor, c-kit, during liver regeneration from putative stem cells in adult rat. Lab Invest 70:511-516. 
Galimi F, Bagnara GR, Bonsi L, Cottone E, Follenzi A, Simeone A, and Comoglio PM (1994). Hepatocyte growth factor induces proliferation and differentiation of multipotent and erythroid hemopoietic progenitors. J Cell Biol 127:17431754.

Galli SJ, Zsebo KM, and Geissler EN (1994). The kit ligand, stem cell factor. Adv Immunol 55:1-96.

Gibson JD, Pumford NR, Samokyszyn VM, and Hinson JA (1996) Mechanism of acetaminophen-induced hepatotoxicity: Covalent binding versus oxidative stress. Chem Res Toxicol 9:580-585.

Gotoh A, Takahira H, Mantel C, Litz-Jackson S, Boswell HS, and Broxmeyer HE (1996). Steel factor induces serine phosphorylation of Stat3 in human growth factor-dependent myeloid cell lines. Blood 88:138-145.

Inokuchi K, Yamaguchi H, Tarusawa M, Futaki M, Hanawa H, Tanosaki S, and Dan K (2000). Abnormality of c-kit oncoprotein in certain patients with chronic myelogenous leukemiapotential clinical significance. Leukemia 16:170-177.

Jacobs-Helber SM, Penta K, Sun Z, Lawson A, and Sawyer ST (1997). Distinct signaling from stem cell factor and erythropoietin in HCD57 cells. J Biol Chem 272:6850-6853.

Jiang WG and Hiscox S (1997). Hepatocyte growth factor/ scatter factor, a cytokine playing multiple and converse roles. Histol Histopathol 12:537-555.

Kay MA and Fausto N (1997). Liver regeneration: Prospects for therapy based on new technologies. Mol Med Today 3:108-115.

Lee SS, Buters JT, Pineau T, Fernandez-Salguero P, Gonzalez FJ (1996). Role of CYP2E1 in the hepatotoxicity of acetaminophen. J Biol Chem 271:12063-12067.

Leigh BR, Khan W, Hancock SL, and Knox SJ (1995). Stem cell factor enhances the survival of murine intestinal stem cells after photon irradiation. Radiat Res 142:12-15.

Liebmann JAM, DeLuca AM, Epstein A, Steinberg SM, Morstyn G, and Mitchell JB (1994). Protection from lethal irradiation by the combination of stem cell factor and tempol. Radiat Res 137:400-404.

Lukacs NW, Strieter RM, Lincoln PM, Brownell E, Pullen DM, Schock HJ, Chensue SW, Taub DD, and Kunkel SL (1996). Stem cell factor (c-kit ligand) influences eosinophil recruitment and histamine levels in allergic airway inflammation. J Immunol 156:3945-3951.

Mauro MJ and Druker BJ (2001). STI571: Targeting BCR-ABL as therapy for CML. Oncologist 6:233-238.
Omori M, Omori N, Evarts RP, Termoto T, and Thorgeirsson SS (1997). Coexpression of flt-3 ligand/flt-3 and SCF/c-kit signal transduction system in bile-duct-ligated $\mathrm{SI}$ and $\mathrm{W}$ mice. Am J Pathol 150:1179-1187.

Papadimitriou CA, Topp MS, Serve H, Oelmann E, Koenigsmann M, Maurer J, Oberberg D, Reufi B, Thiel E, and Berdel WE (1995). Recombinant human stem cell factor does exert minor stimulation of growth in small cell lung cancer and melanoma cell lines. Eur J Cancer 31:2371-2378.

Prescott LF and Critchley JA (1983). The treatment of acetaminophen poisoning. Annu Rev Pharmacol Toxicol 23:87-101.

Rao MS, Yukawa M, Omori M, Thorgeirsson SS, and Reddy JK (1996). Expression of transcription factors and stem cell factor precedes hepatocyte differentiation in rat pancreas. Gene Expr 6:15-22.

Rathbun WB, Killen CE, Holleschau AM, and Nagasawa HT (1996). Maintenance of hepatic glutathione homeostasis and prevention of acetaminophen-induced cataract in mice by L-cysteine prodrugs. Biochem Pharmacol 51:1111-1116.

Ricotti E, Fagioli F, Garelli E, Linari C, Crescenzio N, Horenstein AL, Pistamiglio P, Vai S, Berger M, Montezemolo LC, Madon E, and Basso G (1998). C-kit is expressed in soft tissue sarcoma of neuroectodermic origin and its ligand prevents apoptosis of neoplastic cells. Blood 91:2397-2405.

Timens W and Kamps WA (1997). Hemopoiesis in human fetal and embryonic liver. Microsc Res Tech 39:387-397.

Turner AM, Zsebo KM, Martin F, Jacobsen FW, Bennett LG, and Broudy VC (1992). Nonhematopoietic tumor cell lines express stem cell factor and display c-kit receptors. Blood 80:374-381.

Von Schweinitz D, Schmidt D, Fuchs J, Welte K, and Pietsch $\mathrm{T}$ (1995). Extramedullary hematopoiesis and intratumoral production of cytokines in childhood hepatoblastoma. Pediatr Res 8:555-563.

Wershil BK, Tsai M, Geissler EN, Zsebo KM, and Galli SJ (1992). The rat c-kit ligand, stem cell factor, induces c-kit receptor-dependent mouse mast cell activation in vivo. Evidence that signaling through the c-kit receptor can induce expression of cellular function. J Exp Med 175:245-255.

Williams R (1996). Classification, etiology, and considerations of outcome in acute liver failure. Semin Liver Dis 16:343-348.

Zsebo KM, Smith KA, Hartley CA, Greenblatt M, Cooke K, Rich W, and McNiece IK. (1992). Radioprotection of mice by recombinant rat stem cell factor. Proc Natl Acad Sci USA 89:9464-9468. 